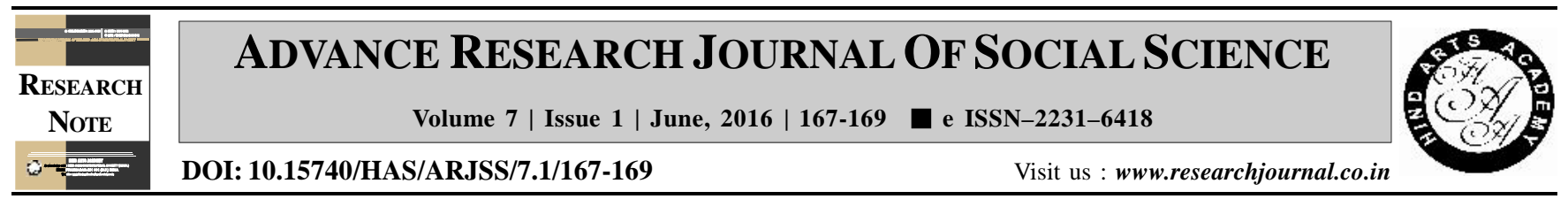

\title{
A scheme of mid day meal scheme and its impact on health of primary classes (6-11 yrs) in Meerut region
}

Praggya Sharma

Kasturba Gandhi Balika Vidyalaya, AGRA(U.P.) INDIA

(Email: rlalitsharma@yahoo.com)

\section{ARTICLE INFO :}

Received : 22.05 .2016

Accepted : 30.05 .2016
KEY WORDS : Scheme of mid day meal scheme, Health primary classes

HOW TO CITE THIS ARTICLE :

Sharma, Praggya (2016). A scheme of mid day meal scheme and its impact on health of primary classes (6-11 yrs) in Meerut region. Adv. Res. J. Soc. Sci., 7 (1) : 167-169, DOI: 10.15740/HAS/ ARJSS/7.1/167-169.
The concept of mid day meal scheme has a long history in India. In 1925 a mid day meal scheme was introduced for children belonging to poor socio-economic status in Madras Municipal Corporation area. In 1928 Keshav Academy of Calcutta (Kolkata) introduced compulsory mid day tiffin for school boys on payment basis at the rate of four annas per child per month.

In 1941, in parts of Kerala, the school lunch programme was started. In 1942 Mumbai started implementing a free mid day meal scheme. A mid day meal scheme was introduce in Banglore city in 1946 to provide cooked rice and yoghurt. In 1953, Uttar Pradesh government introduce a scheme on voluntary basis to provide meals consisting of boiled or roasted or sprouted grams, ground nut, puffed rice, boiled potatoes or seasonal fruits.

In the 1950's many states came to introduce mid day meal scheme with the assistance of different international agencies like UNICEF, FAO and WHO. International voluntary/charity organizations like Catholic Relief services CWS, CARE, USA's Meal Millions etc. During 1958-59 an expanded nutritions programme (ENP) jointly by FAO, WHO, UNICEF and government of
India was introduced.

Mid day meal scheme was also provided to the tribal areas in some states like Madhya Pradesh and Orissa. By 1990-91 the number of the states implementing the mid day meal programme with their own resources on a universal or a large scale had increased to twelve states.

\section{Mid day meal scheme in Uttar Pradesh :}

The mid day meal scheme in Uttar Pradesh covers around one lakh primary schools and related institute and covers 1.86 crore children. The mid day meal scheme provides for nutritious, well cooked and warm food to the children during lunch in at least 200 in a year. U.P. government has nominated following organizations for social audit and government aided primary schools and the for the children enrolled in E.G.S, and A.I.I. enters.

- To develop the grasping process of children through making nutritious food available to them.

- To enhance the enrollment of children in schools.

- To develop the tendency to say in schools in the children and to reduce the drop out rates in schools.

- To develop the feelings of brotherhood/sisterhood 